\title{
INVESTIGATING EFFECTIVE METHODS OF DESIGNING SONIFICATIONS
}

\author{
Michael Quinton, Iain McGregor and David Benyon \\ Edinburgh Napier University, School of Computing, \\ Merchiston Campus, 10 Colinton Road, Edinburgh, \\ EH10 5DT, United Kingdom \\ \{m.quinton, i.mcgregor, d.benyon\}@napier.ac.uk
}

\begin{abstract}
This study aims to provide an insight into effective sonification design. There are currently no standardized design methods, allowing a creative development approach. Sonifcation has been implemented in many different applications from scientific data representation to novel styles of musical expression. This means that methods of practice can vary a greatly. The indistinct line between art and science might be the reason why sonification is still sometimes deemed by scientists with a degree of scepticism. Some wellestablished practitioners argue that it is poor design that renders sonifications meaningless, in-turn having an adverse effect on acceptance. To gain a deeper understanding about sonification research and development 11 practitioners were interviewed. They were asked about methods of sonification design and their insights. The findings present information about sonification research and development, and a variety of views regarding sonification design practice.
\end{abstract}

\section{INTRODUCTION}

The purpose of this study was to investigate effective methods of designing and evaluating sonifications. Guidelines have been developed to facilitate practitioners in their work, but sonification design also enjoys an open ended and creative approach [1]. There are still difficulties for newcomers to the field to understand the basis for good design. Brazil [2] argued that it was hard for new practioners' to understand how to design auditory displays due to guidance being limited and scattered across publications. It is often unclear for what purpose the sonification was designed and for whom. Sonifications are often restricted to contained studies without further development. A lot of publications give little information about the data gathering process and it is often hard to follow why certain design decisions were made. In order to reap a deeper understanding of the sonification design process it was thought necessary to interview practitioners about projects that they had worked on and to investigate their design processes. This publication addresses the results obtained from these interviews and discusses reflections obtained about sonification development and research.

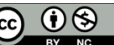
Attribution - Non Commercial 4.0 International License.

The full terms of the License are available at

http://creativecommons.org/licenses/by-nc/4.0/

\subsection{Sonification and Methods of Sonification}

Sonification can be defined as non-verbal sound used to represent data [1]. It is a subset of Auditory Displays, broadly defined by Walker \& Nees [3] as any display using sound to relay information. Sound is a temporal phenomenon and sonification can be effective at representing time based data [4]. Scientific data is usually sonified using either: Audification or Parameter Mapping Sonification.

Kramer's [5] definition of audification cited by Dombois \& Eckel [6] describes it as being the direct translation of data waveforms into sound. The waveform itself might not even belong to the sound domain. The use of amplitude, pitch or equalisation to modify a wave and reveal previously inaudible data, can be classified as an audification.

Parameter Mapping is when data values are mapped using various acoustic attributes (Pitch, Amplitude, Timbre, Rhythm and Spatial Dimensions). This is determined by the data source and available synthesis parameters. Appropriate data preparation determines the success, especially with a multivariate dataset. Dimension reduction techniques must be implemented or complementary derivatives can be added. Data Dimension Reduction is influenced by two factors. The dimensions of synthesis parameters must be utilised as fully and efficiently as possible. Noise or distortion resulting from the parameter mapping must be eliminated to ensure accurate perception. The mapping procedure poses two challenges. The first to ensure that a proper formalization connecting factual data to the elusive nature of the perceptual domain has been achieved. The second that there is good mapping ensuring that the data and its synthesis achieve perceptually valid results [7].

\subsection{Sonification Design}

Dubus \& Bresin [8] citing Scaletti [9], state sonification only becomes relevant if it is communicating original information comprehensibly. Hermann [1] developed four steps that could aid effective sonification. Sound must reflect objective properties or relations to the input data, echoing Scaletti's [9] statement about the importance of the semantic accuracy of sonification portraying data. The second step calls for systematic transformation of data. In that it is precisely defined, and users can comprehend how changes in the data are directly related to changes in the sound. The third step states that the sonification should be reproducible. The same data and similar sonic interactions should sound identical to the original. For a sonification design to be precisely replicated it is important for the original designer to convey comprehensible and effective guidelines that others can easily follow. The fourth step states 
that a sonification system should be able to be utilised repeatedly with different or identical data.

Sonification design has been compared to visualisation and argued that well established visual practices are partly to blame for sonification's restricted appeal amongst scientists. Listening to scientific data has been criticised as being broadly subjective and deemed unscientific [10]. The immersive and emotional qualities of sound seem to reinforce this claim negating sonification being recognised as an accepted scientific method, and seen merely as an art [11].

The comparison between sonification and visualisation does not only reflect differences but also similarities. Any form of design practice methods in sonification, visualisation or $\mathrm{HCI}$ design are a constant learning process that evolve over time. Advances in technology and social trends determine the way that design evolves. Accumulative, collected, knowledge acquired is usually compiled to reflect the design practice within a field and to establish codes of practice or methods. In the sonification community a 'Sonification Handbook' was collated by Hermann and Hunt in 2011 [12]. It contained the ideas of leading practitioners in the field and established definitions, terms and guidelines to assist practitioners and help bring about an established code of design practice.

There are however various publications about sonification research that tend to lack relevant information about the design approach used in the study. It is often hard to understand for what purpose the sonification was designed, for whom and how design decisions were taken. Frauenberger [13] analysed 82 submissions published in ICAD 2007 and found that only 23 of the publications described the design of the auditory display. Verona and Peres [14] identified that many sonifications had not been empirically evaluated adding further lack of understanding of how to design sonifications for specific tasks.

\subsection{Requirements Gathering}

The importance of a thorough investigation of a data-set is also echoed in Barrass's [15] sonification design method "TaDa" (Task-oriented, Data-sensitive method for auditory information design). This method is based on four design principles. The first is "Scenario Description" or a short narrative, in the form of a research question, describing the information process activity that the sonification is designed to support. The second step, "Requirements Analysis", means that requirements must be in line with the research question. It must provide an answer that can be analysed and from which data is characterised from the requirements process. The third principle is about "Representation Design" acquired from the requirements process that are useful to the task and true to the data. Once the investigation and understanding of the data has been established the "Realisation" of the sonification can be fulfilled. The importance of appropriate data gathering and implementation of task analysis methods has been emphasised in multiple sonification papers [15], [16], [3], [17], [18], [19].

\subsection{Designing for End-users}

Many sonifications have been created without involving endusers. This means that the user is unaware of what elements of the data the sonification parameter mappings are representing. Black et al. [20] describes how the use of auditory displays in image guided intervention has been largely neglected despite its benefits. Future work could include working more closely with auditory display designers to create more meaningful displays [20]. The problem of not including end users in the design process was identified by Kramer et al. [21] in 1997 and has yet to be fully resolved. He stated that sonification research needs to be user and task centred. Although it had been successful in a broad range of application areas, it was still not clear as to how to design an effective, working sonification for a specific task. This could be a reflection of open ended design approach and not a failure in the design process. Kramer suggested that progress in sonification would require specific research directed at developing predictive design principles or design guidelines. Sonification is naturally task dependant, requires adequate representation for data portrayal and user interface interaction. The report describes a number of considerations that should be taken into account when designing a sonification (see table 1).

Table 1 Guidelines for designing a sonification user interface

\begin{tabular}{|l|l|}
\hline Considerations & Descriptions \\
\hline Control & $\begin{array}{l}\text { Parameter controls for sound parameters that are efficient, } \\
\text { effective \& accessible }\end{array}$ \\
\hline Mapping & $\begin{array}{l}\text { Provides flexibility \& the ability to design new sonification } \\
\text { mappings allowing the user to have intuitive control over data } \\
\text { dimensions in relation to sound parameters }\end{array}$ \\
\hline Integrability & $\begin{array}{l}\text { To allow the different formats of data from different } \\
\text { disciplines to be imported into the system and then sonified }\end{array}$ \\
\hline Synchrony & $\begin{array}{l}\text { To allow easy integration with other display systems like VR } \\
\text { systems and other visual or assistive technologies }\end{array}$ \\
\hline Experimentation & $\begin{array}{l}\text { To integrate a perceptual framework for testing overall } \\
\text { mapping functions and sound synthesis }\end{array}$ \\
\hline
\end{tabular}

Source:- Kramer et al. [21]

\subsection{Evaluation Methods used to test Sonifications}

There is often an open-ended approach to sonification design but patterns are noticeable in the way practioners map parameters [22]. A total of 22 publications were chosen and analysed to explore sonification design. These publications were selected since they reflected a variety of applications of sonification and followed different design methods. This indicated the diversity of sonification application. There were publications about sonifications that were created for the same field of study, showing the different design approaches taken by various practitioners to represent similar aspects of data. Eleven had not been tested and the papers only discussed their sound design methods [23], [24], [25], [26], [27], [28], [29], [30], [31], [32], [33]. The other eleven publications [34], [35], [36], [37], [38], [39], [40], [41], [42], [43], [14] were evaluated by investigating their methods of data gathering, whether they chose audification or parameter mapping, if there was training prior to testing, the testing procedure itself, the results and any mentions of further development of the sonification.

\subsection{Requirement Gathering Methods}

Effective methods of practice typically follow a rigorous investigation to learn about the data. Most sonification designs are constructed by first obtaining information from relevant literature [34], [35], [38], [39], [40]. Other sonification designs were based on conducting interviews with the proposed endusers [36], [37], [41], [42], [43], [14]. Two publications did not explain clearly how the requirements or data gathering processes were conducted. These publications were "Not Informative" [36], [37]. Two studies gave detailed 
explanations about the type of information that was gathered but were vague about how it was gathered. These publications were "Partly Informative" [41], [43]. There were two publications that gave a clear explanation of the data gathering investigations, which were "Informative" [42], [14]. Requirements and data gathering were often under-reported in publications. Out of the 6 reports that conducted interviews or involved an enduser in the design process, only two gave descriptive information about these procedures. Some publications gave ample information about the data but were scarce on reporting how it was obtained.

\subsection{Parameter Mapping Techniques}

Parameter Mapping descriptions are occassionally not accessible or easy to grasp. Table 2 gives an indication of mappings that were found in each of the publications that had some form of testing. Boschi et al. [34] has been included in the table to indicate the testing methods but used audification as a sonification technique to categorise seismic signals. Vertical-Component recordings of the November 2011 magnitude 5.6 Oklahoma Earthquake made at 17 stations (< $500 \mathrm{~km}$ ) epicentral distances were speeded up from $40 \mathrm{~Hz}$ to 6 $\mathrm{kHz}$ in pitch and from 300 to 2 seconds of playback time.

The most common parameter mapping is the use of pitch. Most of the sonifications analysed for this study involved multiple mappings where more complex representations of the data were required. The exceptions Brewster \& Murray [35] who only mapped pitch to movements in stock prices and Schaffert et al. [41] who mapped pitch using Middle $C$ as a zero point and notes above and below being higher or lower to that point.

Table 2 Parameter Mappings, Test Methods \& Results

\begin{tabular}{|l|l|l|l|l|l|c|}
\hline Author & Data & Mappings & Participants & Training & $\begin{array}{l}\text { Positive } \\
\text { Results }\end{array}$ & $\begin{array}{l}\text { Negative } \\
\text { Results }\end{array}$ \\
\hline 34 & Earthquake & * Audification & 24 & Yes & $\boldsymbol{V}$ & $\mathbf{x}$ \\
\hline 35 & Financial & $\begin{array}{l}\text { Pitch - up (higher) } \\
\text { down (lower) }\end{array}$ & 12 & Yes & $\boldsymbol{V}$ & $\boldsymbol{V}$ \\
\hline 36 & Financial & $\begin{array}{l}\text { Pitch, Tremolo, Note } \\
\text { length }\end{array}$ & 12 & Yes & $\boldsymbol{V}$ & $\mathbf{x}$ \\
\hline 37 & Oil Well & $\begin{array}{l}\text { Pitch, Tone, } \\
\text { Amplitude }\end{array}$ & 20 & Yes & $\boldsymbol{V}$ & $\boldsymbol{V}$ \\
\hline 38 & Alzheimers & Pitch, Rhythm, Tone & 2 & No & $\boldsymbol{V}$ & $\boldsymbol{V}$ \\
\hline 39 & ECG & $\begin{array}{l}\text { Pitch, Amplitude, } \\
\text { Harmonics }\end{array}$ & 22 & Yes & $\boldsymbol{V}$ & $\mathbf{X}$ \\
\hline 40 & $\begin{array}{l}\text { Motor Skill } \\
\text { Learning }\end{array}$ & Noise, Pitch, Rhythm & 45 & Yes & $\boldsymbol{V}$ & $\boldsymbol{V}$ \\
\hline 41 & Rowing & Pitch & 23 & Yes & $\boldsymbol{V}$ & $\mathbf{x}$ \\
\hline 42 & Piloting Aircraft & $\begin{array}{l}\text { Pitch, Rhythm, Tone, } \\
\text { Syllables }\end{array}$ & 17 & Yes & $\boldsymbol{V}$ & $\boldsymbol{V}$ \\
\hline 43 & Internet Log Data & $\begin{array}{l}\text { Tone, Note Length, } \\
\text { Rhythm, Amplitude }\end{array}$ & $\begin{array}{l}\text { Analysed by } \\
\text { research team }\end{array}$ & No & $\boldsymbol{V}$ & $\boldsymbol{V}$ \\
\hline 14 & $\begin{array}{l}\text { Surface } \\
\text { Electromyography }\end{array}$ & $\begin{array}{l}\text { Pitch, Amplitude, } \\
\text { Panning, Filter }\end{array}$ & 43 & No & $\boldsymbol{V}$ & $\mathbf{x}$ \\
\hline
\end{tabular}

\subsection{Test Methods and Results}

In some instances participant training prior to testing was needed (see table 2). Eight sonifications had some form of training. Negative results were only reported by 5 of the designers. By giving a more positive overview of sonification's effectiveness it could be portraying a false indication of the general effectiveness of sonification.

\subsection{Further Development of the Sonification Design}

Out of the 11 studies that were evaluated only 4 publications provide information about future work [36], [38], [34], [37]. In the case of Jamieson \& Boase [43], a general overlook on the future of work on sonification is presented but there is no specific information about further development of their sonification model.

\subsection{Obtaining more information about Sonification design}

To obtain more information about sonification design it was decided that it would be worth interviewing sonification designers. Grounded Theory was used as a method of investigation for this study. It investigates what occurs in the research setting and explores how they explain statements or actions. The data collected is then studied and compiled through an analytical process. The researcher has to be open to what is happening in the studied scenarios and the interview statements. Grounded theory methods consist of systematic, yet flexible guidelines for qualitative data collection and analysis which are used to construct theories 'grounded' in the data themselves. The data is simultaneously collected and analysed it is separated, sorted and synthesised through a process of qualitative coding. Analytical codes and categories are created from the data and not from pre-existing conceptualisations. The researcher seeks to discover any social processes reflected in the data. Once the data has been sorted into categories these are integrated into a theoretical framework [44].

\section{METHOD}

Grounded Theory was used as a method of investigation for this study. Semi Sturctured interviews were conducted to ask practitioners about the purpose of their sonification, the design, testing, results, and the outcome of the study. The 11 participants had designed sonifications for a variety of applications. Some of them have developed guidelines about the sonification design process. Participants were recruited by email. Eighteen people were initially contacted and 14 replied. Contact details were obtained from ICAD publications. A variety of sonification researchers were chosen with different degrees of experience in the field. One side of the scale consisted of well established members who have heavily contributed to the field. The other side were people just starting in sonification research and development. This was done with the intention of obtaining a rich spectrum of different perspectives, knowledge and ideas concerning sonification design. The University ethical procedures were followed. This included the provision of a participant information sheet and an informed consent form. The questions were based around the design processes of specific projects and sonification design in general.

A different set of questions were asked to one participant who was interested in talking about sonification design guidelines. These questions were aimed to learn more about the effectiveness of these guidelines, how these assist practitioners and whether or not they are being applied.

\subsection{Procedure}

Participants were contacted via Skype and the interviews were recorded on a portable audio recorder. Due to qualitative approach of the investigation no pilot study was conducted, allowing the interviews to evolve and be adaptable to each of the interviewees. Participants were asked questions about sonification design according to the outcome of the interview. Some people spoke about a specific project. Others discussed various projects giving details on how each sonification was designed. The interviews were approximately one hour long. 
Each interview was transcribed and coded. The coding procedure passed through three different phases of extraction and refinement. The first phase was to obtain an initial set of codes and descriptors from the participants' responses. The second phase was to refine the codes and definitions and to see what was meaningful or redundant. The third and final phase was to check for consistency in the results. No form of interrater reliability was conducted due to the use of Grounded Theory as a method of investigation.

\section{RESULTS}

A total of 11 people were interviewed about sonification design. Participant's experience in sonification design varied. The more seasoned sonification designer's seemed to have a more global perspective about the workings of sonification design. Those who were newer to the field often spoke more about their sonification projects and the experiences encountered during the design processes.

\subsection{Different Opinions and Common Ground}

Paul Vickers (PV) made reference to the first ICAD conference: "really you can trace it back to, in terms of where things really took off, was 1992 with the first ICAD." Certain practioners believe that sonification has been successful within this limited time frame. Bruce Walker (BW) clearly states that: "I know absolutely, it is being used more and more." Whereas Steven Barrass (SB) argues that the use of sonification is "Pretty low or Zero really". When asked about effective sonification design Keith Nesbitt (KN) replied that: "Some of the questions that you asked have been and are still being asked also about visualisation." The common ground shared by the designers was that the sonification design process is challenging. Daniel Verona (DV) metions how: "It's not easy to do a direct correlation between the design criteria and the mapping". KN describes that even a well prepared design could sometime falter: "Trying to come up with understanding how to design these displays, your best laid plans can often go astray". These views are echoed by Philart (P): "This is what we are doing including users and do participatory design, but still it's not really perfect". In other disciplines of design such as HCI and Visualisation there are two key factors that are common practice. It is clear who the product is designed for, and users are involved in the design process. The second is that numerous iterations of the design are made. These practices have become more common in sonification design over the years, and all the participants spoke about these processes when describing data gathering and design exercises.

\subsection{Data Gathering Process and Comprehension}

All the practioners discussed how they had consulted with people that they were designing for, or those that were related to the design process. In other instances the designers had run mock tests with preliminary designs to improve their models. Jamie Ferguson (JF) described how there was a continuous back and forth interaction with the European Space Agency, ESA, in the design of his sonification of star maps: "So they were pretty much on the ball with you. They would give you feedback on it and you would improve the model according to the feedback." Robert Alexander (RA) also described this process by stating: "I needed to first learn their approach and what's unique about their dataset. And then it became a back and forth dialogue." RA's thorough investigation of the dataset he was sonifying led him to change his approach from using parameter mapping to audification: "I had decided to go to the other route and actually, really use direct audification to try to find, really, again, you know, subtle and nuanced features." It was this switch to audification that led to a ground-breaking discovery in the study of solar astronomy (RA): "It was the audification work that led to the new scientific discoveries, which then led to the published papers". The discovery itself helped scientists to change their methods of research and it was through RA's sonificatios that this became possible: "I was listening to carbon 6 to 4 and what ended up happening was that no one had looked to deeply into the 6 to 4 ratio and then when we went back and plotted it, it was pretty easy to see that carbon is much kind of smoother curve." As P had pointed out: "Sometimes sonification is very successful and sometimes just...nothing". BW explains that: "Getting it right requires careful planning, information architecture, a lot of knowledge in the field, mastery of the tools".

$\mathrm{KN}$ refers to the importance of iterative prototyping: "The best approach these days is to try something and provide iterative prototyping". This means that numerous discussion are held between the users and the designers. Tests are conducted with different versions of the sonification and improvements are made according to the results.

$\mathrm{P}$ described the sonification design of emotional conveyance of dancer's movements. The team consists of dancers, musician and sound designers. The movements of the dancers are recorded whilst they danced to music that evoked certain emotions in them. These movements were then given to the musicians and the sound designers and designed sound and music that convey the emotions reflected in the dancers movements. A survey was then carried out with 20 participants to see which of the three final designs worked best. (P) "We just finished a very basic survey type study with around 20 participants, non-dancers, they are just college students." BW describes the complexity of designing any kind of interface and that inter-disciplinary knowledge is required for effective sonification design: "It's hard work and requires interdisciplinary teams and broad background to get it right.".

Gionfrida (LG) described how: "We proposed different tune structures, thinking they would sound better at the time but they were more difficult for physicians to understand." LG's final sonification reaped positive results: "There was essentially an increase (improvement) between how they performed without sonification and how they performed with sonification". That is why the investigation and design process is essential for an effective sonification design, as clearly stated by SB: "Design and design research is a real critical enabler in this field."

Clearly identifying the scope of a sonification project is an important factor and DV emphasised this in his sonification design. DV was convinced that by using a Task Analysis approach a sonification could be much more effective. To explore this he designed two sonifications using a Task analysis technique known as GOMS and two were data-based designed. DV describes how: "My task based sonifications performed quite a bit better than my non-task or data based sonifications". It proved that: "Designing for a specific task can help listeners perform the task with the sonification". 
One other essential part of the investigation process is reference to the literature. To obtain knowledge a designer has to learn about the subject by following currently existing models or prototypes that have been designed and tested. The interviews presented a number of arguments that reflected a weakness in this aspect of the sonification design process.

\subsection{Limitations in Sonification Literature}

There was shared concern about the lack of descriptions of sonification design processes in the literature of the field. DV described this by stating that: "What I found so frustrating in sonification literature was, there was hardly ever any explanation of why a specific mapping or why a specific frequency range was chosen". SB also expresses certain limitations with the literature on the subject: "A lot of their assumptions (the designers) are built into their decision making and they are the only ones that understand the rationale. And even when you read their papers with very little explanation about stuff, it's still assumptions that have never been tested". PV describes: "If you look at the literature, a lot of it is still one off, bespoke, sonification systems with studies that are narrow in scope so the results are not that generalizable". This point was further emphasized by BW "It's either part of a class or a Master's thesis and they pick it up over the course of a semester. They [students] are still obviously novices and even if they do very well, the chances are they haven't learned enough".

There was also the mention of a lack of vocabulary in sonification design. Mark Ballora (MB) clearly states that sonification: "Just doesn't have the established vocabulary that visualisation does". He also refers to Carla Scaletti's comments in her ICAD 2017 keynote that also emphasizes this point: "So she was talking about, that it doesn't have an established vocabulary (Sonification)." Other fields of study such as Human Factors and Ergonomics design and Visualisation have an established vocabulary. DV argues: "If there is a language of design that is familiar to people outside our community, then suddenly there is a less of a gap to cross between our work and their work (Human Factors and Ergonomics design).

\subsection{Sound Design and Parameter Mapping}

\subsubsection{Mimicking Nature \& Using Associative Anchors}

MB states that: "Natural sounds, sounds that mimic nature, sounds that are completely abstract, it's all project specific". Sometimes the obvious association to a sound is required in the sound design. SB describes it as: - "If people want to hear rainfall then they should hear rainfall. If the task is to hear the amount of rain then you should hear that as the amount of rain, not the pitch of a Cello." MB also used mappings that mimicked the sound of the wind in a sonification that represented Meteorological storm data: "Sometimes the storms get more intense but they don't get more symmetrical and she can't see that so readily from the videos but she could certainly hear it from the sonifications". The use of familiar sounds was also voiced by Dyer (JD): "Real world objects make sounds in certain ways and those can be a good starting point for design". The familiarity of sound often acts as an anchor and this is taken into consideration when designing a sound and mapping it. Ferguson (JF) describes this anchoring as: "try to tap into that, when people hear these things, they can begin to make analogies about it". PV also describes how easily people make the connection with more natural sounding designs: "When you do the sound design you have to be aware that any sound you create can have an association with the real world, in fact, people are possibly going to reach for it."

\subsubsection{Simple Mappings}

Simple sonification design is at times the necessary way to effectively map a dataset. The neural mappings described by LG were systematically organised to allow simple parameter mappings to effectively represent the data and achieve highly positive results: "You can get lost with a lot of information. That information has to be very simple, straightforward". The simple sonic representation employed by LG still revolved around a mutli-layered sound design, not complex, but consisting of more elements to enhance the semantic representation of the data. DV describes how his sonfication consisted of simple sound design of more complex representations than simple one on one mapping: "We can ascribe meaning to a sound, but we're not going to ascribe meaning to a sound based on one dimension of sound. Not just based on pitch, it's a big combination of all these different things". JD had also expressed the effectiveness of simple sonification mappings: "It was informative just because of its ease of use".

\subsubsection{Psychoacoustic Elements}

The psychoacoustic elements of sound design play an integral part in parameter mapping. There are elements that could be more effective than others (BW): "if you are using something like frequency then you have the built in possibility of these logarithmic relationships" and (BW): "But amplitude is somewhat unreliable. People are quite poor at discerning levels of amplitude". Elements of Rhythmic representation are an easy association, and also have a temporal effect that are difficult to represent visually. JD describes how Rhythmical elements helped in coordinating movement of users in motion gesture sonification: "Trajectories of movement when you're trying to time yourself quite precisely, tend to be more accurate if you go for this strategy, ballistic (Sound)".

\subsubsection{Aesthetics}

Aesthetics in Sound Design are a key element in the effectiveness of a sonification and MB clearly states that: "I think the aesthetics are critical to it." BW echoes this: "Aesthetics absolutely plays a crucial role in any kind of technology. Sound is absolutely included in that. Something has to sound good, and also has to sound right". Sonifications can easily become unwanted sounds $(\mathrm{KN})$ : "Things can sound like noise". It is this element of noise that has often led people to switch sonifications off (JF): "What I've discussed with most people is that the problem with sonification is that most people turn them off'. This doesn't necessarily mean that the sonifications sound unpleasant. Many of the researchers insisted that aesthetics does not mean that the sound designs have to necessarily sound pleasing. PV sees this as a problematic simplification " $a$ lot of sonification researchers view aesthetics simply though the lens of 'Does it sound nice?"'. SB agrees with this: "I don't think of aesthetics in terms of pleasantness or decoration. I'm much more vested in the idea of like I think that if it is efficient it will be aesthetic". 


\subsection{About Positive Results of Sonification Testing}

The sonification designs discussed in these interviews were not all tested scientifically. Those that were reaped positive results. Those that weren't tested had some form of positive feedback. It can be agreed that sonification is most effective in representing temporal information. There are cases when sonification can out perform visualisation and this is usually when the user is unable to refer to a screen and needs some form of data feed in order to carry out a task. This is apparent with forms of motion guided systems. The literature reflects positive testing results but still seems to remain within the realm of isolated tests and this presents a false positive about the success rate of sonification and it's use beyond testing.

\subsubsection{Sonification Testing - An Isolated Success Story}

The discussion concerning Sonification testing and results concluded that many were done in isolation. Positive outcomes can give a false positive as to the success of sonification. MB criticises this approach and it's limited perception of the bigger picture: "A lot of the papers that you read it's like kind of bleep bloopy and they did a pilot test with 20 people and they got this out of it so by golly this is worthy of further research." SB describes how the testing should be about evaluating current methods, as there is no proof that these mappings actually work, rather than constantly trying to prove that sonification works: "the most common technique in sonification, it's still pitch mapping and it's hardly ever been evaluated". SB goes on to criticise current testing techniques: "There's a big difference between hypothesis testing and knowledge building". PV describes a more daunting scenario: "I don't think we've learnt very much about sonification design." This could be due to a lack of understanding from the designers part and PV goes on to say that: "I think that we have a lot of sonifications that don't really do what they're doing with an understanding of the wider perceptual issues."

With all the testing that has taken place sonification still has not become a more widely accepted data analysis tool. This is probably the yard stick with which many designers in the Community are measuring the success of sonification.

\section{DISCUSSION}

The interviews give a clear picture of what sonification is, its potential when designed correctly and that despite these efficiencies, sonification has still not become a more accepted tool for scientific data representation and analysis procedures. There are those who have criticised sonification literature and have pointed to lack of certain details that could help convey vital knowledge to any that would be interested in using the tool. Brazil [2] had identified how daunting it could be for a person who is trying to learn about sonification design from the literature. Verona had expressed this frustration too in his interview comments and had also expressed a further frustration towards lack of clarity in most publications. His comments clearly stated that: "Maybe because of that people just weren't designing for the task or maybe if they were, they weren't explaining how they did that in their papers". Frauenberger [10] had also found these 'holes' in sonification literature where the descriptions of auditory display designs were lacking.

One of the main issues that have been highlighted is that a lot of sonification designs are contained projects, often dissertations or isolated studies. Many of these studies involve people who are new to the field, who have to learn as much as they can within a limited time frame and to create an effective sonification. This probably means that a lot of sonification designs lack the necessary knowledge, skillset or the lifespan to exist beyond the confines of that project. Walker had described how this was a common feature in all types of design scenarios: "The vast majority of software, just in general, are built and go nowhere. I think that we also see the same kind of thing with sonifications."

This lack of knowledge from the designer's angle could be one of the reasons why many sonifications are redundant. It is like the metaphor of 'the blind leading the blind'. And it could also be the reason why the field has not yet established a common vocabulary. This is where sonification differs from Human Interactive fields and Visualisation, which both have established vocabularies. The majority of sonification designs analysed for this study lacked Task Analysis design methods. Kramer et al. [18] had outlined this problem in 1997 and Barrass [12] also proposed Task Analysis design techniques in 1996. The emphasis for appropriate data gathering has been echoed in many publications [12], [13], [3], [14], [15], [16]. The only study which used Task Analysis in the papers that were analysed was the Verona \& Peres [11] study. Task Analysis design methods could help to form a vocabulary for sonification design. This means that a lot still has to be learned. As Vickers commented: - "I think our knowledge of sonification design and theory is still fairly primitive."

\subsection{It Works}

There are those that have a more positive outlook towards where sonification is at the moment and where it is heading. BW strongly believes that sonification is being utilised: "Scientific sonification is being used more. It's being used in oil and gas exploration and circumstances where there's a lot of data. It's being used in financial services, investment context, engineering and space exploration. Most of these situations where even the best visual displays are still not doing it. Multimodal, time varying complex patterns, all the kinds of situations where we point, to sonification and say that it's likely to succeed." One of the reasons why there is a lack of reporting of the more widespread use of sonification is that (BW): "We don't hear about all of those contexts. Some of those things, especially the financial investing and oil discovery, the big companies are not going to advertise the fact that they are using these specialised tools." Philart was reluctant to measure the success of sonification because it depends on the context. The use of sonification in industry is often overlooked and as an example $\mathrm{P}$ describes the incident where he purchased a washing machine and found that the sound design was the same one he had created 10 years earlier: "When the washing machine cycled down the pitch generated a melody that I composed....ok seems successful. It's like 10 years later they still use that sound.". P did go on to say that in academia, the success of sonification is different: "But it is really hard to see that type of consistency in academic research.". LG sees a strong potential in the use of sonification, especially in instances where the user cannot look at a visual display due to the task that they are carrying out. This is extremely prevalent in the medical realm: "What I have always been thinking is that in the medical domain, they actually always rely on the visual information and they should actually rely more on the auditory feedback as well." 


\subsection{Not Yet Maybe Later}

There are those that are not seeing any current progress but strongly believe it is a potential tool and that it will come into acceptance in the future. This more positive view towards the direction of sonification is based on the fact that most sonification designers believe that people in general are not really taught how to listen. $\mathrm{KN}$, in describing how the visual component in humans is more dominant states the following: "This is part of the problem in terms of making sonification more broadly used, is that there is just a stronger visual preference for many people and their hearing senses are under-utilised, under-trained." PV also identifies this issue: "What we should be aspiring to is much greater skill in our listening." MB strongly believes that the sophistication of the human hearing faculty automatically leans towards sonification becoming an accepted data analysis tool: "That's the thing about sound. That's why I think it is inevitable that this becomes a part of our environment because the human animal is so responsive to sound."

\section{SUMMARY}

The results give an indication of how each step of the design process is currently being practiced by sonification designs. It also portrays the complexity of sonification design and the contrasting views regarding design, testing, the outcome and effect of sonification. The main elements that can be highlighted from these results is that effective sonification design requires in-depth investigation of the data, the inclusion of the user in the design process, a valid number of iterations in choice of sonification technique, parameter mapping and sound design. The testing of the sonification has to be well studied and should reflect the overall scope of the sonification design. One time testing is ineffective and gives false positives. The testing process should be considered as further iteration of the design procedure. To rate how successful sonification is in general, there is a divided outlook with regards to this, but there is an overall concensus that much more work has to be done to improve sonification design and implementation. Even though opinions are divided about the current status of sonification's present implementation in scientific research, there is a positive outlook and common belief that sonification will become an accepted and widely used means of data representation.

\section{ACKNOWLEDGMENTS}

Acknowledgement and thanks go to all those that participated in this study: James Ferguson, Robert Alexander, Myounghoon 'Philart' Jeon, Bruce Walker, Mark Ballora, Steven Barrass, Keith Nesbitt, John Dyer, Letizia Gionfrida, Paul Vickers \& Daniel Verona

\section{REFERENCES}

[1] Hermann, T. (2008). Taxonomy \& definitions for sonification \& auditory display. In P.; Susini \& O. Warusfel (Eds.), . Paris, France: International Conference on Auditory Display 2008 (ICAD 2008). Retrieved from http://www.icad.org/Proceedings/2008/Hermann2008.pd f

[2] Brazil, E. (2010), A review of methods and frameworks for sonic interaction design: Exploring existing approaches. Auditory Display $-6^{\text {th }}$ International
Symposium, CMMR/ICAD 2009, Copenhagen, Denmark, May 18-22, 2009, Revised papers, Volume 5954 of lecture notes in Computer Science, pages 41-67. Springer, 2010

[3] Walker, B., \& Nees, M. (2011). Theory of Sonification. Principles of Sonification: An Introduction to Auditory Display and Sonification, The Sonification Handbook Chapter 2, (November), 1-32. Retrieved from http://sonify.psych.gatech.edu/publications/pdfs/2006pre print-WalkerNees-SonificationChapter v09.pdf

[4] Vickers, P., Holdrich, R (2017), "Direct Segmented Sonification of the data domain", arXiv pre print, arXiv:1711.11368, 2017, arxiv.org

[5] Kramer, G. (1994). Auditory Display: Sonification, Audification and Auditory Interfaces. Addison-Wesley, Reading (MA). Proceedings Volume 18, Santa Fe Institute Studies in the Sci (Book 18), 672 pages, CRC Press (June 7, 1994), ISBN-10: 0201626047

[6] Dombois, F., \& Eckel, G. (2011). Audification. In T. Hermann, A. Hunt, \& J. G. Neuhoff (Eds.), The Sonification Handbook. Logos Publishing House, Berlin. Retrieved from http://sonification.de/handbook/index.php/chapters/chapt $\underline{\operatorname{er} 12 /}$

[7] Grond, F. and Berger, J. (2011). Parameter Mapping Sonification. In T. Hermann, A. Hunt and J.G. Neuhoff (eds.) The Sonification Handbook. Berlin: Logos, 36397.

[8] Dubus, G., and R. Bresin. 2013. "A Systematic Review of Mapping Strategies for the Sonification of Physical Quantities.” PLOS ONE 8(12):e82491.

[9] Scaletti C (1994) Auditory display: sonification, audification and auditory interfaces, Addison Wesley Publishing Company, chapter 8: Sound synthesis algorithms for auditory data representations. pp. 223-251

[10] Supper, A. (2016) Lobbying for the ear, listening with the whole body: the (anti-)visual culture of sonification, Sound Studies, 2:1, 69-80, DOI: 10.1080/20551940.2016.1214446

[11] Supper, A. (2014). Sublime frequencies: The construction of sublime listening experiences in the sonification of scientific data. Social Studies of Science, 44(1), 34-58. http://doi.org/10.1177/0306312713496875

[12] Hermann, T., \& Hunt, A. (2011). The Sonification Handbook (1st ed.). Berlin: Logos Publishing House, Berlin. Retrieved from http://sonification.de/handbook/

[13] Frauenberger, C. (2009), Auditory Display Design: An investigation of a design pattern approach. $\mathrm{PhD}$ dissertation., Interaction, Media, and Communication, Queen Mary University of London, 2009, p 59

[14] Verona, D., \& Peres, S. C. (2017). A Comparison Between the Efficacy of Task-Based vs. Data-Based sEMG Sonification Designs. In Proceedings of the 23rd International Conference on Auditory Display (ICAD 2017)(pp. 49-56)

[15] Barrass, S. (1997). Auditory Information Design. The Australian National University Australia, 288. Retrieved from

http://citeseerx.ist.psu.edu/viewdoc/download?doi=10.1. 1.127.6228\&amp;rep=rep1\&amp;type $=$ pdf

[16] Anderson, J., (2005), "Creating an Empirical Framework for Sonification Design," in Proceedings of ICAD 05 Eleventh Meeting of the International Conference on Auditory Display, 2005, pp. 393-397.

[17] Flowers, J., (2005), "Thirteen Years of Reflection on Auditory Graphing: Promises, Pitfalls, and Potential New 
Directions," in Proceedings of ICAD05 - Eleventh Meeting of the International Conference on Auditory Display, 2005, pp. 406-409.

[18] Sanderson, P., Anderson, J., Watson, M., (2000), "Extending Ecological Interface Design to Auditory Displays," in Proceedings of the 2000 Annual Conference of the Computer-Human Interaction Special Interest Group (CHISIG) of the Ergonomics Society of Australia, 2000, pp. 259-266.

[19] Peres, S.C, \& Verona, D (2016), “A Task-Analysis-Based evaluation of sonification designs for two sEMG tasks", The $22^{\text {nd }}$ International Conference on Auditory Display (ICAD 2016), July 2nd - 8th, 2016 Canberra, Australia

[20] Black, D., Hansen, C., Nabavi, A., Kikinis, R., and Hahn, H., (2017) "A survey of auditory display in image-guided interventions," Int. J. Comput. Assist. Radiol. Surg., pp. 1-12, 2017. http://doi.org/10.1007/s11548-017-1547-z

[21] Kramer, G., Walker, B., Bonebright, T., Cook, P., Flowers, J. ., MIner, N., \& Neuhoff, J. (1997). Sonification report: Status of the field and research agenda. Retrieved from http://www.icad.org/websiteV2.0/References/nsf.html

[22] Ibrahim, A. A. A., Yassin, F. M., Sura, S., \& Andrias, R. M. (2011). Overview of design issues and evaluation of sonification applications. 2011 International Conference on User Science and Engineering (I-USEr ). http://doi.org/10.1109/iUSEr.2011.6150541

[23] Ness, S., R., Reimer, P., Krell, N., Odowichuck, G., Schloss, W., A., \& Tzanetakis, G. (2010). Sonophenology: A tangible interface for sonification of geo-spatial phonological data at multiple time scales. The $16^{\text {th }}$ International Conference on Auditory Display (ICAD-2010), 335-341

[24] Ben-Tal, O., Berger, J., Cook, B., Daniels, M., Scavone, G., Cook, P., (2002), "SONART: The Sonification Application Research Toolbox", Proceedings of the 2002 International Conference on Auditory Display, Kyoto, Japan, July 2002

[25] de Campo, A., Dayé, C. (2006), "Navegar e preciso, viver nao e preciso", The $12^{\text {th }}$ International Conference on Auditory Display, , June 20-23 2006, London

[26] Kadkhodaie, A. Rezaee, R. (2017), "Have you ever head the sound of well logs or reservoir data?", Journal of Petroleum Science and Engineering, 156 (2017) 340 - 347

[27] McGee, R., Rogers, D., 2016. Musification of seismic data. In: The 22nd International Conference on Auditory Display (ICAD-2016). Canberra, Australia.

[28] Polli, A. (2005), Atmospherics/weather works: A spatialized meteorological data sonification project. The $10^{\text {th }}$ International Conference on Auditory Displays (ICAD), pages 31-36, Sydney, Australia, July 2004.

[29] B. Sturm (2000), "Sonification of particle systems via de Broglie's hypothesis," Proceedings of the 7th International Conference on Auditory Display,Atlanta, GA, April 2-5, 2000

[30] Vogt, K. (n.d.), "Sonification and Particle Physics", Department of theoretical physics, Institute for physics, Karl - Franzens - University Graz Austria, Institute for Electronic Music and Acoustics, University for Music and Dramatic Arts Graz, Austria, katharina.vogt@uni-graz.at, Retrieved $16^{\text {th }} \quad$ April 2018, from, https://www.researchgate.net/profile/Katharina Vogt/pu blication/228592750 Sonification and particle physics/ links/02e7e51ca83485c5f5000000/Sonification-andparticle-physics.pdf
[31] Winton, J., Gable, T. M., Schuett, J. \& Walker, B. N. (2012), "A sonification of kepler space telescope star data," in Proceedings of the 18th International Conference on Auditory Display, Atlanta, GA, 2012.

[32] Barrass, S., \& Zehner, B. (2000). Responsive sonification of well logs. In P. Cook (Ed.) Proceedings of the 7th International Conference on Auditory Display (pp. 72 80). Atlanta, GA: International Community for Auditory Display, April 2-5, 2000

[33] Baier G, Hermann T, Stephani U (2007) Event-based sonification of EEG rhythms in real time. Clinical Neurophysiology 118: 1377-1386.

[34] Boschi, L., Pate, A., Holtzman, B., Le Carrou, JL. (2015), "Can auditory display help us categorize seismic signals?", The $21^{\text {st }}$ International Conference on Auditory Display (ICAD-2015), July 8-10, 2015, Graz, Austria

[35] Brewster, S., Murray, R., (2000): Presenting Dynamic Information on Mobile Computers. Personal Technologies 4(2), 209-212

[36] Janata, P., and Childs, E. (2004). Marketbuzz: Sonification of real - time finan cial data. Paper presented at the 10th Inernational Conference on Auditory Displays, Sydney, Australia. July 2004

[37] Quintero, G., 2013. Sonification of oil and gas wireline well logs. In: The $19^{\text {th }}$ International Conference on Auditory Display. Pp. 301-306, 6-10 July, Poland.

[38] Gionfrida, L., Agnieszka, R., Keary, J., Mohanraj, H., Friedman, Kent P., (2016), The Triple Tone Sonification Method to enhance diagnosis of Alzheimer's Dementia, the 22nd International Conference on Auditory Display. July 2016, Canberra, Australia

[39] Kather, J-K. Hermann, T. Bukschat, Y. Kramer T., Schad, L., \& Zãüllner. F-G (2017), "Polyphonic sonification of electrocardiography signals for diagnosis of cardiac pathologies." Scientific Reports 7 (2017), 44549.

[40] Dyer, J. Stapleton, P. Rodger, M. (2016), “Sonification movement for motor skill learning in a novel bimanual task: Aesthetics \& Retention Strategies", School of Psychology \& Sonic Arts Research Centre, Queens University Belfast, The $22^{\text {nd }}$ International Conference on Auditory Display (ICAD-2016), Canberra, Australia

[41] Schaffert N, Gehret R, Mattes K (2012) Modeling the rowing stroke cycle acoustically. Journal of the Audio Engineering Society 60: 551-560.

[42] Valery, B., Scannella, S., Peysakhovich, V., Barone, P., Causse, M., (2017), Can an aircraft be piloted via sonification with an acceptable attentional cost? A comparison of blind and sighted pilots, Applied Ergonomics, Volume 62, July 2017, PP 227-236, https://doi.org/10.1016/j.apergo.2017.03.001

[43] Jamieson, J. Boase, J. (2017), "Listening to Social Rhythms: Exploring logged interactional data through sonification", The Sage handbook of social media research methods, Thousand Oaks, CA: Sage Publications

[44] Charmaz, K. (2006), "Constructing Grounded Theory: A Practical Guide Through Qualitative Analysis", SAGE Publications Ltd 1 Oliver's Yard 55 City Road London EC1 Y1SP, ISBN-10 0-7619-7352-4 